\title{
Laboreal
}

Volume $7 \mathrm{~N}^{\circ} 2$ | 2011

Varia

\section{Condições de trabalho das pessoas imigrantes e seus efeitos na saúde : abordagem multimétodo}

Condiciones de trabajo de las personas inmigrantes y sus efectos en la salud:

abordaje multimétodo

Les conditions de travail des personnes immigrées et leurs effets sur la santé :

démarche multiméthode

Working conditions for immigrant individuals and its effects on health :

multimethod approach

María José López-Jacob

\section{OpenEdition}

\section{Journals}

Edição electrónica

URL: http://journals.openedition.org/laboreal/7860

DOI: $10.4000 /$ laboreal. 7860

ISSN: 1646-5237

Editora

Universidade do Porto

Refêrencia eletrónica

María José López-Jacob, « Condições de trabalho das pessoas imigrantes e seus efeitos na saúde abordagem multimétodo », Laboreal [Online], Volume $7 \mathrm{~N}^{\circ} 2$ | 2011, posto online no dia 01 dezembro 2011, consultado o 24 setembro 2020. URL : http://journals.openedition.org/laboreal/7860 ; DOI : https://doi.org/10.4000/laboreal.7860

Este documento foi criado de forma automática no dia 24 setembro 2020.

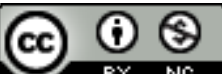

Laboreal está licenciado com uma Licença Creative Commons - Atribuição-NãoComercial 4.0 Internacional. 


\section{Condições de trabalho das pessoas imigrantes e seus efeitos na saúde : abordagem multimétodo}

Condiciones de trabajo de las personas inmigrantes y sus efectos en la salud: abordaje multimétodo

Les conditions de travail des personnes immigrées et leurs effets sur la santé:

démarche multiméthode

Working conditions for immigrant individuals and its effects on health :

multimethod approach

María José López-Jacob

\section{REFERÊNCIA}

López-Jacob, M. J. (2010). Condiciones de trabajo de las personas inmigrantes en España y sus efectos en la salud. Abordaje multimétodo. Tesis doctoral en Epidemiología y Salud Pública, Universidad Rey Juan Carlos, Madrid.

\section{NOTA DO EDITOR}

Manuscrito recebido em : Junho/2011

Aceite após peritagem : Outubro /2011

\section{Introdução}

1 A recente e massiva chegada a Espanha de imigrantes económicos, principalmente desde a última década do século XX, acarretou uma mudança manifesta nos padrões 
sociodemográficos, na vida das escolas, nos bairros, nos centros de saúde, nos centros de emprego; mas, sobretudo, significou uma mudança nas condições de vida das pessoas que empreenderam a aventura de abandonar o seu país. A procura de um futuro melhor através da integração no mercado laboral, é o principal impulso que estimula o recente processo migratório em Espanha (Vila-Velda, 2004) e as características do mercado de trabalho espanhol e das ocupações em que se inserem, são importantes determinantes das condições de trabalho em que estes trabalhadores se movimentam.

2 Existe clara evidência sobre o facto de que os trabalhadores imigrantes realizam os trabalhos mais perigosos e as ocupações menos qualificadas (Eamranond \& $\mathrm{Hu}, 2008$ ), (Fundación Europea para la Mejora de las Condiciones de Vida y Trabajo, 2007), em especial na construção, serviços domésticos, hotelaria, comércio e actividades de limpeza (García, 2009) denominadas segundo a terminologia anglo-saxónica como "as três D" por dirty, demanding and dangerous (OIT, 2004).

Em Espanha é muito escassa a informação sobre as condições de trabalho das pessoas imigrantes e o efeito que estas têm sobre a saúde, sendo que para elas o trabalho é o elemento central dos seus projectos e trajectórias migratórias.

A abordagem ao estudo da saúde e das condições de trabalho destes trabalhadores não é fácil. A complexidade do estudo dos factores laborais que podem afectar a saúde incorporam dificuldades derivadas da situação deste colectivo no mercado de trabalho concreto a que chegaram. As situações de precariedade, irregularidade administrativa e o limitado acesso a determinados serviços determinam, além disso, a "invisibilidade" da sua presença nas fontes de informação tradicionalmente utilizadas na investigação em saúde pública.

5 Com a finalidade de contribuir para melhorar esta situação, durante o período de 2006-2008 desenvolveu-se um projecto de investigação coordenado entre quatro universidades espanholas (Universidade Pompeu-Fabra de Barcelona, Universidade de Alicante, Universidade de Huelva, Universidade de Valencia) e um Instituto Sindical (ISTAS) ; o projecto, denominado "Imigração, Trabalho e Saúde (ITSAL) mediante o uso de fontes de dados primários e secundários e uma combinação de técnicas qualitativas e quantitativas, teve como objectivo geral aprofundar o conhecimento das condições de emprego e de trabalho e a sua relação com a saúde dos trabalhadores imigrantes em Espanha.

6 Neste artigo apresentam-se os resultados mais relevantes do projecto, de que a autora participou e que fazem parte da sua dissertação de tese de doutoramento apresentada em 2010 e foi orientada pelos professores Ángel Gil e Fernando G. Benavides.

\section{Resultados}

\section{Um maior risco de acidente de trabalho}

7 A análise das bases de dados oficiais que recolhem a informação gerada pela notificação obrigatória dos acidentes de trabalho em 2005 permitiu comparar o risco de lesões entre os trabalhadores espanhóis e estrangeiros (López-Jacob, Ahonen, García, Gil \& G. Benavides, 2008). Os resultados mostraram um risco maior, em termos de Risco Relativo, dos trabalhadores estrangeiros em comparação com os autóctones, tanto para 
as lesões mortais $(1.34,1.11-1.62)$ como para as não mortais $(1.13,1.13-1.14)$. As diferenças encontradas entre Regiões Autónomas e Actividades Económicas sugerem a existência de notificação e sub-declaração do sistema de notificação que afectam de maneira específica o colectivo de trabalhadores estrangeiros.

O Inquérito Nacional de Condições de Trabalho (ENCT) realizado em 2007 pela primeira vez nas residências (em alternativa às empresas), foi analisado com o mesmo objectivo de comparação, neste caso entre trabalhadores espanhóis e trabalhadores procedentes de países com índice de desenvolvimento humano (IDH) inferior a 0.9 (RubialesGutiérrez, Agudelo-Suárez, López-Jacob \& Ronda-Pérez, 2010). Os resultados mostraram um maior risco de acidente nos trabalhadores de baixo IDH em comparação com os espanhóis (1.28, 1.07-1.52), em especial nas mulheres (1.41, 1.06-1.88), nos compreendidos entre 45 y 64 anos $(1.82,1.25-2.64)$ e trabalhadores independentes desta procedência $(1.98,1.12-3.51)$.

\section{A invisibilidade das condições de trabalho das mulheres no sector doméstico}

9 Do material de campo recolhido na fase qualitativa do projecto (entrevistas em profundidade e grupos de discussão) em que participaram 158 participantes (68 mulheres, 99 homens), seleccionaram-se para esta análise específica os dados de 46 mulheres que trabalhavam no serviço doméstico (Ahonen et al., 2010).

10 As participantes caracterizaram como comuns os problemas de exposição a riscos de tipo ambiental (fundamentalmente substâncias químicas de limpeza), embora tenham dado maior importância aos riscos de tipo ergonómico e os riscos de saúde associados ; em termos gerais, definem o trabalho no sector como extenuante e identificam as frequentes dores musculares como originadas pelo trabalho. As que desempenham fundamentalmente tarefas de limpeza descrevem problemas derivados de movimentos repetitivos e rigidez postural, enquanto que as que se ocupam com cuidar de pessoas dependentes referem uma maior exposição a sobre-esforços e a um risco elevado de lesões nas costas. Não obstante, os problemas narrados com maior riqueza prendem-se com os aspectos psicossociais. Grandes exigências emocionais quantitativas, escassa percepção de apoio, escassa influência, insegurança, monotonia, etc., configuram umas condições de trabalho com elevado impacto na saúde das participantes, que coincidem em assinalar problemas de stresse, de sono, ansiedade, cansaço e tristeza. No contexto "doméstico" marcado pelo isolamento, em especial para as empregadas "internas", a ausência de informação, a inaplicabilidade da legislação de riscos laborais, e a deficiente regulação normativa específica do sector constituem parte dos elementos que determinam a invisibilidade dos problemas deste colectivo.

\section{Determinantes de influência nas condições de trabalho dos trabalhadores imigrantes}

11 Com a finalidade de descobrir os determinantes da influência dos trabalhadores imigrantes nas suas condições de emprego e de trabalho tendo em conta a percepção dos imigrantes sobre o papel dos sindicatos sobre este assunto, ampliou-se o trabalho de campo da fase qualitativa acima esboçada com uma amostra de participantes que, para além de satisfazer os critérios estabelecidos de trabalhador imigrante, incluíram a 
característica de serem representantes sindicais. Os resultados da análise descrevem as dificuldades dos trabalhadores imigrantes para influir nas suas condições de trabalho (López-Jacob et al., 2010). A escassa informação sobre direitos e as deficientes relações laborais detectadas (incumprimento da legislação laboral, relações de submissão, percepção de hostilidade) apenas são parte do problema ; as características do mercado de trabalho e as circunstâncias decorrentes da situação migratória dos participantes configuram um contexto em que os participantes se encontram sem ferramentas de negociação a não ser a sua força de trabalho, num ambiente no qual se lhes faz sentir com frequência a sua qualidade de substituíveis. Os imigrantes representantes sindicais informam de uma experiência similar à do início do processo migratório, contudo acrescentam uma visão complementar derivada da sua pertença a um sindicato; identificaram necessidades específicas das organizações sindicais para melhorar as suas estratégias de difusão em torno de direitos laborais à luz das suas próprias experiências, assinalaram a importância das redes sociais (no que coincidem com os restantes participantes), nas quais eles próprios desenvolvem as suas actividades, à diferença, segundo relatam, dos sindicatos autóctones e destacam a importância da existência "real" e simbólica do papel dos sindicatos como determinante de influência.

\section{Conclusão}

12 O conjunto de resultados do projecto ITSAL descreve sérios problemas nas condições de trabalho e saúde dos imigrantes em Espanha, sobre os quais havia poucos estudos desenvolvidos. Tornaram-se manifestas condições de emprego deficientes, condições de trabalho perigosas e diversos danos à saúde que os afecta de forma diferencial e sobre as quais até ao momento havia escassa evidência. A integração de diversas metodologias qualitativas e quantitativas facilitou a abordagem do estudo neste colectivo enormemente diverso e deficientemente representado nas fontes de dados habitualmente utilizadas em saúde pública.

13 A irrupção da crise económica, que se iniciava na fase final do projecto, abre novas interrogações sobre o impacto na saúde no conjunto das pessoas a que é preciso dar resposta. Os trabalhadores imigrantes constituem um grupo especialmente vulnerável aos efeitos desta crise (Awad, 2009) através de mecanismos de desemprego, precariedade e empobrecimento sobre os quais já há evidência.

\section{BIBLIOGRAFIA}

Ahonen, E. Q. et al. (2010). Invisible work, unseen hazards: the health of women immigrant household service workers in Spain. American Journal of Industrial Medicine, 53, 4, 405-16.

Awad I. (2009). The global economic crisis and migrant workers: Impact and response. International Migration Programme. International Labour office ; citado 18 mar 2010. Disponible en : http:// www.ilo.org/public/english/protection/migrant/download/global_crisis.pdf 
Eamranond, P. P., \& Hu, H. (2008). Environmental Exposures in Immigrant Health. Environmental Health Insights, 1, 45-50.

Fundación Europea para la Mejora de las Condiciones de empleo y de Trabajo. (2007). Employment and working conditions of migrant workers. Disponible en: www.eurofound.europa.eu/ewco/studies/ tn0701038s/

García, A. M., López-Jacob, M. J., Agudelo-Suárez, A. A., \& Ruiz-Frutos, C. (2009). Condiciones de trabajo y salud en inmigrantes (Proyecto ITSAL) : entrevistas a informantes clave. Gac Sanit. 23, (2), 91-99.

International Labour Office (2004). Towards a fair deal for migrant workers in the global economy. Citado 18 marzo 2010. Disponible en : www.ilo.org/public/english/standards/relm/ilc/ilc92/pdf/ rep-vi.pdf

López-Jacob, M.J., Ahonen, E., García, A.M., Gil, A., \& Benavides, F.G. (2008). Lesiones por accidente de trabajo en trabajadores extranjeros por actividad económica y comunidad autónoma (España, 2005). Revista Española de Salud Pública, 82, 5, 179-87.

López-Jacob, M.J., Canaleta, E., García, A.M., Garí, A., Agudelo-Suárez, A.A., Gil, A. \& Benavides, F.G. (2010). Participation and influence of migrant workers on working conditions: a qualitative approach. New Solutions, 20 (2), 225-238.

Rubiales-Gutiérrez, E., Agudelo-Suárez, A.A.; López-Jacob, M.J., \& Ronda-Pérez, E. (2010).

Diferencias en los accidentes laborales en España según país de procedencia del trabajador. Salud Pública de México, Mayo-Junio, 199-206.

Vila-Belda, A. J. (2004). La población inmigrada en España. Economistas, 99, 6-14.

\section{AUTOR}

\section{MARÍA JOSÉ LÓPEZ-JACOB}

Instituto Sindical de Trabajo Ambiente y Salud (ISTAS), C/ General Cabrera, 21 - bajo, 28020

Madrid - España

mljacob@istas.ccoo.es 